Revista

Ibero-Americana

de Estratégıa

\title{
ESTRATÉGIAS DE ESTÍMULO AO EMPREENDEDORISMO CORPORATIVO
}

\section{STRATEGIES FOR FOSTERING CORPORATE ENTREPRENEURSHIP}

\section{Leonel Cezar Rodrigues}

Professor e pesquisador do Programa de Mestrado e Doutorado da Universidade Nove de Julho UNINOVE

E-mail: leonel@uninve.br (Brasil)

\section{Emerson Antonio Maccari}

Professor e pesquisador do Programa de Mestrado e Doutorado da Universidade Nove de Julho UNINOVE

E-mail: emerson@uninove.br (Brasil)

\section{Alexsandro Pereira}

Administrador de empresas pela Universidade Nove de Julho - UNINOVE

E-mail: alexsandro.pereira1@gmail.com (Brasil) 


\title{
ESTRATÉGIAS DE ESTÍMULO AO EMPREENDEDORISMO CORPORATIVO
}

\section{RESUMO}

O presente artigo tem por objetivo analisar e caracterizar as estratégias corporativas utilizadas pela Brasilata - Embalagens Metálicas S/A, uma das mais premiadas empresas brasileiras por suas inovações, para estimular o empreendedorismo corporativo em sua organização. O método aqui utilizado foi o estudo de caso, com coleta de dados de entrevista pessoal com diretores da empresa, observação dos processos, normas e procedimentos internos e busca de informações em documentos e relatórios. Os principais resultados mostram que, devido ao empreendedorismo corporativo, a empresa pesquisada, tem tido um aumento de produtividade da ordem de $81 \%$. Foram examinadas cerca de 46.000 idéias, até essa pesquisa e depositadas 6 patentes, que respondem por $75 \%$ do faturamento anual da empresa. Isto evidencia que nessa empresa, as estratégias de estímulo ao empreendedorismo são efetivas, garantem resiliência à empresa, melhoram seu desempenho e dão sustentabilidade ao seu negócio.

Palavras-chave: Empreendedorismo Corporativo; Estratégia Corporativa; Inovação; Inovação Corporativa.

\section{STRATEGIES FOR FOSTERING CORPORATE ENTREPRENEURSHIP}

\begin{abstract}
This paper targets at analyzing and characterizing corporate strategies practiced at Brasilata Metallic Packing S/A, one of the most innovative and world-wide awarded Brazilian enterprises, to stimulate corporate entrepreneurship. This research used the case study research method. Data were collected from interviews with corporate executives, from studying internal reports and documents, observing processes, norms and specific procedures. Main results show that due to corporate entrepreneurship, Brasilata improved its productivity to $81 \%$. Some 46,000 new ideas have been examined and also 6 patents were granted, which account for $75 \%$ of the enterprise annual revenues. Evidences show therefore, that corporate entrepreneurship's strategies are effective at Brasilata and do create corporate resilience and improve performance bolstering business sustainability.
\end{abstract}

Keywords: Corporate Entrepreneurship; Corporate Strategy; Corporate Innovation.

Revista Ibero-Americana de Estratégia - RIAE, São Paulo, v. 8, n. 2, p. 183-205, jul./dez. 2009. 
Leonel Cezar Rodrigues, Emerson Antonio Maccari \& Alexsandro Pereira

\section{INTRODUÇÃO}

A constante geração de soluções de novos caminhos a problemas comuns pode ser percebida não somente como obra do homem, mas também como uma fórmula evolutiva da própria natureza. $O$ estudo da história e evolução das espécies mostra que de maneira geral, estar em transformação é uma das constantes presentes e todos os sistemas. Sistemas só conseguem sobreviver se se adaptarem. Sistemas que nunca se adaptam às mudanças de seu entorno, tendem ao desaparecimento no curto ou no longo prazo. Esse processo, observado e descrito por Darwin nos seres vivos é perceptível também nas organizações. Empresas sem renovação estratégica, originada em suas capacidades de inovar, estão destinadas à obsolescência e ao conseqüente desaparecimento. $\mathrm{O}$ século $\mathrm{XX}$, palco do florescimento da maioria das organizações, tem mostrado e sido testemunha da aceleração deste processo. Tecnologias tendem a diminuir seu ciclo de vida, e nesse processo diminuem o ciclo de vida de produtos e de mercados.

Sob o ponto de vista do amadurecimento organizacional, quanto mais consolidada a empresa, maior seu nível de regramento e divisionalização do trabalho (Adizes, 1996). Isto cria condicionamentos burocráticos que, pelo engessamento das regras, desmotivam iniciativas de profissionais talentosos e inovadores. Em conseqüência, também cria uma corrente de deshabilitação da organização em inovação, impedindo-a de evoluir e adaptar-se aos desafios de seu entorno competitivo. Para evoluir adaptativamente a empresa precisa construir mecanismos que aumentem sua resiliência interna (REINMOELLER; BAARDWIJK, 2005), habilitando-a a enfrentar mais eficientemente as mudanças em seu meio de operação. Resiliência, no entanto, é alcançada pela construção de equipes criativas e auto-gerenciadas, particularmente por meio do incentivo ao surgimento de empreendedores corporativos, como agentes de inovação.

Se as empresas apropriarem seus ambientes interno ao florescimento de pessoas inovadoras, não é mais preciso sair da empresa e montar seu próprio negócio para ser empreendedor. Qualquer pessoa pode ser empreendedora, sem sair de sua empresa (PINCHOT III, 1989). Basta, para tanto, que as estratégias corporativas, na taxonomia de Miles; Snow (1986), formulem mecanismos de estímulo ao empreendedorismo corporativo. Para tanto, as estratégias corporativas precisam apropriar estruturas, sistemas, processos e recursos que estimulem a presença de empreendedores dentro do ambiente interno das empresas (PINCHOT III; PELLMAN , 2004).

Revista Ibero-Americana de Estratégia - RIAE, São Paulo, v. 8, n. 2, p. 183-205, jul./dez. 2009. 
Estratégias de Estímulo ao Empreendedorismo Corporativo

\subsection{PROBLEMA E OBJETIVO}

As empresas da era pós-industrial vivenciam um momento de hiper-competição (DRUCKER, 2002), que requer delas a combinação de estratégias corporativas, organizacionais e competitivas, para fazer frente aos permanentes desafios de mercado. Neste contexto de desafios, a inovação aparece como a arma mais eficaz para aumentar a capacidade competitiva das empresas. De fato, a observação e o estudo permanente das tendências e comportamentos dos setores industriais e das atividades sócio-econômicas no mundo levaram a World Future Society, no início desta década, a apontar esta como a era da inovação. Esta era é caracterizada por um elevado nível de competição empresarial, pela forte dependência da informação, pela horizontalização dos negócios, pelo uso de tecnologias inteligentes e pelo novo papel do homem na empresa. Com o advento das tecnologias inteligentes, comandadas integradamente pela tecnologia de informação e da crescente pressão pela inovação em produtos e negócios, as empresas vêem-se obrigadas a ampliar o valor econômico da inovação, tanto na criação, quanto, e principalmente, na captura do valor, para garantir retorno e lucratividade a seus negócios.

Nesse contexto, o homem passa a ter papel central, pois é dele que dependem a criatividade, a usabilidade e a funcionalidade das novas idéias. É a esse homem, criativo e inovador, que chamamos de Empreendedor Corporativo, para o qual é necessária a construção de mecanismos de estimulo à construção de valores que tornem a inovação central nos processos empresariais.

Desta forma, é objetivo deste artigo, estudar as estratégias de estímulo ao empreendedorismo corporativo, numa empresa selecionada. Para tanto, pretende-se identificar e analisar as políticas, diretrizes e ações voltadas para estimular o empreendedorismo corporativo, numa empresa selecionada, a Brasilata S.A., uma empresa classificada e premiada entre as dez empresas mais empreendedoras do Brasil, em 2006, pela Revista Exame.

Estudos como o aqui proposto podem contribuir significativamente para as práticas gerenciais e para o corpo de conhecimentos sistematizados em empreendedorismo. Ainda que o empreendedorismo corporativo encontre-se em fase incipiente, tanto a validação de modelos conceituais e de comportamento de empreendedores, quanto o estudo de políticas e diretrizes de estímulo ao empreendedorismo corporativo são importantes mecanismos de subsídio às corporações interessadas em iniciar ou aperfeiçoar sua capacidade de inovar, aumentando sua imunidade às pressões competitivas em seu ambiente de operação.

Revista Ibero-Americana de Estratégia - RIAE, São Paulo, v. 8, n. 2, p. 183-205, jul./dez. 2009. 
Leonel Cezar Rodrigues, Emerson Antonio Maccari \& Alexsandro Pereira

\section{FUNDAMENTAÇÃ̃ TEÓRICA}

Um dos fundamentos do empreendedorismo, seja ele independente ou corporativo, é a inovação. Ao empreendedor independente, inovação é importante porque the permite transformar em realidade seu sonho. Ao empreendedor corporativo, inovação é importante porque esta é a razão de se esforço pessoal, de reconhecimento pelos seus pares e de avanço na carreira profissional. Assim, aborda-se aqui a questão da inovação e sua importância no contexto do empreendedorismo e em seguida a questão do empreendedorismo corporativo e das estratégias de estímulo.

\subsection{INOVAÇÃO E NEGÓCIOS}

A inovação é hoje o principal veículo de estímulo à mudança na sociedade (TWISS, 1992) e a mais importante alavanca de transformação de negócios e mercados (MANIYCKA et al. 2007). A vantagem competitiva de uma empresa pode resultar do seu tamanho, ou da posse de determinados ativos, porém, cada vez mais, inovação é uma característica de organizações que conseguem mobilizar conhecimento, capacidades tecnológicas e experiência para criar novidades (produtos e serviços) e para melhor as formas de criá-las e oferecê-las ao mercado (TIDD; BESSANT; PAVITT, 2005). Por isso, organizações competitivas estão aprendendo a moldar a inovação, muito mais do que simplesmente reagir a ela. A razão principal é o fato de que tecnologia per se raramente pode ser apontada como origem da captura do valor econômico. É a empresa que, criando valor em seus produtos ou processos pela inovação, é capaz de capturar valor ao combinar a inovação com novas formas de fazer negócio. Inovação é o fundamento da diferenciação que determina o nível de sucesso das organizações e, por enquanto, é um dos únicos mecanismos que pode garantir sucesso e sustentabilidade aos negócios.

O Manual de Oslo (2005) define inovação como "a implementação de um produto (bem ou serviço) novo ou significativamente melhorado, ou um processo, ou um novo método de marketing, ou um novo método organizacional nas práticas de negócios...” (Oslo, p.55, 2005). Segundo o Manual a inovação em produto ou serviço acontece quando se desenvolve e se disponibiliza um novo produto não existente anteriormente. A inovação de processo implica a "implementação de um método de produção ou distribuição novo ou significativamente melhorado" (Oslo, p.58, 2005). E a inovação de marketing ocorre, segundo o Manual, "na concepção do produto ou em sua embalagem, no posicionamento do produto, em sua promoção ou na fixação de preços” (Oslo, p.

Revista Ibero-Americana de Estratégia - RIAE, São Paulo, v. 8, n. 2, p. 183-205, jul./dez. 2009. 
59, 2005), de forma nova ou significantemente diferenciada. Nitidamente, as definições de inovação do Manual de Oslo, focam como pano de fundo, o negócio. Neste sentido, combinam geração com captura de valor, no processo da inovação. No final das contas, esse é o valor da inovação para os negócios, isto é, gerar mais ou novo valor econômico.

É importante salientar, ademais, que para os negócios, a inovação possui implicações significativas sobre as estratégias organizacionais, as corporativas e as competitivas. Sob o ponto de vista das estratégias organizacionais, as implicações recaem principalmente sobre o ajuste do melhor design estrutural da organização. Em termos das corporativas, sobre as formas de alocação dos novos recursos e desenvolvimento de novas capacidades ou processos. E em termos das competitivas, sobre o posicionamento e atenção a novos segmentos. É dentro dessas premissas que o empreendedorismo corporativo e as estratégias de estímulo ao seu desenvolvimento são aqui abordados, como fundamento da resiliência das empresas e, em conseqüência, da nação como um todo.

\subsection{EMPREENDEDORISMO - GENERALIDADES E CONCEITOS}

A raiz da palavra empreendedor remete-nos ao início do milênio passado onde, segundo Vérin (1982), entrepreneur era o agenciador de brigas (duelos medievais). A palavra evoluiu para chefe de milícia, no século XVII e no século XVIII foi absorvida pela área da economia, significando aquele que se responsabilizava por um projeto econômico: compra matérias primas, transfoma-as em bens e produtos e vende-as a terceiros. O termo "entrepreneur" foi incorporado à língua inglesa no início do século XIX.

Um dos primeiros pensadores a conceituar modernamente a palavra "empreendedor" foi o economista francês Jean Baptiste Say, na primeira metade do século XIX. Say pensava o empreendedor como aquele capaz de gerar recursos econômicos num setor de baixa atividade econômica e transformá-lo num setor de alta atividade econômica.

A popularização do termo empreendedor, no entanto, foi obra do economista Joseph Schumpeter em 1934, com sua tese de doutorado, mais tarde transformada em livro. Segundo Schumpeter, empreendedor é uma pessoa que, por meio de inovações, consegue alterar o perfil econômico de sua empresa ou setor, pela substituição das antigas por novas tecnologias, mais eficientes e de mais baixo custo (inovação destruidora). Schumpeter aponta cinco fontes básicas de inovação: (1) um novo produto ou nova característica de qualidade num produto; (2) um novo método de produção; (3) um novo mercado para um produto; (4) uma nova fonte de suprimentos de

Revista Ibero-Americana de Estratégia - RIAE, São Paulo, v. 8, n. 2, p. 183-205, jul./dez. 2009. 
Leonel Cezar Rodrigues, Emerson Antonio Maccari \& Alexsandro Pereira

matéria prima ou nova matéria prima; e (5) a criação de uma nova ordem num setor industrial ou uma nova estrutura de mercado no setor. As fontes de inovação, segundo o autor, seriam desencadeadas por pessoas com iniciativa, visão e capacidade de realização, a quem ele chama de empreendedores.

Para Filion (1991), o empreendedor é o que sonha (imagina), visualiza sua idéia no futuro e realiza-a. Filion (2000) considera que os comportamentalistas foram os dominadores do conhecimento sobre o perfil do empreendedor, na segunda metade do século passado, onde a questão central estava em identificar quem realmente era o empreendedor e como ele se comportava. Desde então, inúmeras pesquisas voltaram-se para a identificação das características e traços da personalidade do empreendedor. Pati (1995) apresenta uma longa lista com mais de quinze características distintas de um empreendedor bem-sucedido, que envolve habilidades intra e interpessoais. Vries; Manfred (2001) explicitam em mais detalhes as várias características comportamentais de Pati dos empreendedores.

Mais recentemente, os estudos sobre empreendedorismo começam a ser mais ecléticos, envolvendo estes ao pensamento econômico, ao perfil psicológico de líderes de negócio e a padrões de comportamento social (BASTOS; BASTOS, 1999).

Dentre os estudiosos da corrente comportamentalista, McClelland (1961) talvez tenha sido um dos pesquisadores mais importantes por seus estudos sobre o perfil do empreendedor. Esse autor destaca nos empreendedores a necessidade de realização como sua principal característica. Essa necessidade dirige a atenção do indivíduo e concentra suas habilidades na construção de empreendimentos de sucesso. Uma importante recomendação de McClelland é a de que as nações deveriam desenvolver políticas de valorização dos empreendedores a ponto de transformá-los em modelos sociais. Isso induziria as novas gerações a verem os empreendedores como um valor intrínseco e uma decisiva opção de carreira.

\subsection{EMPREENDEDORISMO CORPORATIVO}

Empreendedorismo corporativo, ou intra-empreendedorismo, é uma expressão mais recente no âmbito da área de conhecimento da empreendedologia. Pinchot III(1978) percebeu que o empreendedor descrito por Schumpeter não era apenas aquele indivíduo que constrói uma empresa, mas também aquele que dentro das corporações age de modo pró-ativo e se responsabiliza pela implementação de idéias inovadoras. Ao empreendedor dentro da corporação, Pinchot III chamou de intrapreneur e popularizou o termo na década de 80. Hoje o termo ajustou-se mais à expressão

Revista Ibero-Americana de Estratégia - RIAE, São Paulo, v. 8, n. 2, p. 183-205, jul./dez. 2009. 
empreendedor corporativo, para designar a classe de profissionais que, trabalhando dentro das organizações age como empreendedores, assumindo riscos decorrentes de suas idéias, persistindo na defesa de seus projetos e criando caminhos alternativos para a solução dos desafios originado nas demandas do ambiente de operação das empresas.

Os resultados das pesquisas de Pinchot III; Pellman (2004) indicam que as corporações perdiam oportunidades de melhorar sua própria competitividade porque, em vez de estimularem os criadores a desenvolverem suas idéias dentro da empresa, estimulavam-nos a desistir de seus projetos inovadores ou a abandonar a empresa para implementá-los.

Desta forma, o empreendedorismo corporativo surge dentro da empresa como uma nova filosofia de trabalho, capaz de fomentar a iniciativa individual de tal maneira que os talentos identificados por suas idéias fazem a diferença, na capacidade competitiva da empresa. Por isso, muitas empresas estão começando a despertar para a importância de estimular o lado empreendedor de seus colaboradores, visando a agregar valor para as atividades desempenhadas e iniciar novos projetos internos nos diversos níveis da organização, estimulando a inovação.

Dada a sua crescente importância, o empreendedorismo corporativo tem sido foco de pesquisas acadêmicas nas últimas três décadas e foi definido em sua forma mais abrangente como:

“(...) a combinação de inovação, renovação e esforços de venturing da organização” (ZAHRA, 1995, p. 227). Na verdade, inovação é o fundamento da ação empreendedora corporativa, que provoca, colateralmente, mais um subproduto: a renovação estratégica. Renovação estratégica pode ser definida pela contribuição de visões distintas de vários autores. Pode ser caracterizada pela criação de nova riqueza através da combinação, recombinação ou realocação otimizada de recursos (MINTZBERG, 1987). Isso inclui ações de ajuste estrutural, redesenho da organização, realinhamento de processos e desenvolvimento de capacidades especiais que permitam à empresa entregar valor de forma superior às suas concorrentes. (NADLER; TUSHMAN, 1997; HAMEL; PRAHALAD, 2005).

Empreendedorismo corporativo também tem sido estudado por Kanter (1982) e Birkinshaw (1997). Mais recentemente, novas teorias como a da resiliência organizacional, discutida por Reinmoeller; Baardwijk, (2005), a da ambidestridade organizacional (BIRKINSHAW; GIBSON, 2004) e as relações entre os criadores corporativos e os gerentes de linha (AUSTIN; NOLAN, 2007), dão novas abordagens e maior amplitude contextual às idéias iniciais de Pinchot III; Pellman (2004) e Kanter (1982) sobre empreendedorismo corporativo.

Com base na premissa de que as grandes empresas podem e devem se adaptar ao ambiente competitivo em que operam, estudiosos do empreendedorismo corporativo, entre eles Peters; Waterman (1982), Ghoshal; Bartlett (1999), Kanter (1989), e Tushman; O’Reilly III (1997) 
Leonel Cezar Rodrigues, Emerson Antonio Maccari \& Alexsandro Pereira

sugerem que essa adaptação se deva dar por meio de mudanças na cultura e dos sistemas organizacionais. Tais mudanças induziriam os indivíduos dentro das organizações a agirem de maneira empreendedora, permitindo que se multipliquem o número de idéias passíveis de exploração e a qualidade dos projetos que resultariam dessas idéias (IBIE, 2006).

\subsection{FORMAÇÃO DA CULTURA EMPREENDEDORA NA ORGANIZAÇÃO.}

Uma empresa se organiza com base em seus valores, crenças, procedimentos e atitudes. Este conjunto de intangíveis, partilhados por todos que pertencem a uma empresa, ajuda a definir a cultura desta, a qual é partilhada por todos que dela fazem parte. Assim, o empreendedor corporativo é fruto dessa cultura e sua presença ajuda a construir a história empreendedora da empresa (DOLABELA, 1999; DORNELAS, 2001; DRUCKER,2002).

Drucker (1986) já alertava para a necessidade de uma cultura favorável ao florescimento do espírito empreendedor, se as empresas quisessem comprometimento com a inovação. A ele junta-se Farrel (1993) argumentando que é necessário o desenvolvimento da cultura empreendedora, isto é, uma obsessão pelo conhecimento dos clientes e pelo conhecimento dos produtos da empresa para poder criar o valor percebido e capturar o valor econômico das inovações.

Farrel (1993) aponta empresas conhecidas mundialmente que adotam práticas visando ao desenvolvimento da cultura empreendedora, como a Walt Disney e a 3M entre outras. Na 3M, por exemplo, colaboradores que desenvolvem uma nova idéia, que por sua vez se transforma em um novo produto, têm a oportunidade de liderar o projeto. Essa política é incentivada pela alta direção da empresa, tornando a 3M uma empresa conhecida como das mais inovadoras no mundo.

\subsection{AMBIDESTERIDADE COMO ESTRATÉGIAS AO EMPREENDEDORISMO CORPORATIVO}

Empresas de sucesso, além de inovadoras e proativas são boas em explorar duas importantes capacidades estruturais: o alinhamento e a adaptabilidade. Alinhamento indica criar coerência direcional das estruturas e processos em direção à padronização de processos aumento da produtividade. Adaptabilidade refere-se à flexibilidade adaptativa da organização às variações de seu meio competitivo (BIRKINSHAW; GIBSON, 2004). O desenvolvimento dessas capacidades na organização dá-lhe competências ambidestras, ou ambidesteridade organizacional.

Revista Ibero-Americana de Estratégia - RIAE, São Paulo, v. 8, n. 2, p. 183-205, jul./dez. 2009. 
Para ter sucesso no longo prazo, uma organização precisa equilibrar adaptabilidade e alinhamento. Focar somente em alinhamento e em eficiência de processos pode parecer bom, mas mudanças no seu entorno competitivo irão afetá-la cedo ou tarde, exigindo-lhe a adaptabilidade que não possui. Da mesma forma, foco muito intenso em adaptabilidade debilita sua eficiência operacional, diminuindo seu desempenho e consistência e colocando em sério risco o amanhã de seu negócio à custa do de hoje.

Tradicionalmente, todas as empresas possuem ambidesteridade a estrutural (DUNCAN, 1976), isto é, possuem departamentos que voltam-se para atividades internas (produção, por exemplo) e departamentos com atividades precipuamente externas (como o de Marketing). A combinação dessas atividades dá à empresa uma capacidade ambidestra em seu conjunto, isto é, na empresa como um todo. A departamentalização de atividades e funções na empresa, porém, tem obrigado a alta administração a trazer para si a responsabilidade pela ambidesteridade da empresa, levando a uma evidente perda de otimização das dinâmicas de alinhamento e adaptabilidade, mas principalmente, a perdas oportunidades de inovação. A favorabilidade à inovação, originada na política de ambidesteridade de uma organização depende da amplitude de sua ambidesteridade contextual. Segundo Birkinshaw; Gibson (2004), a ambidesteridade contextual é aquela desenvolvida ao longo da organização como um todo, por meio de atividades flexíveis de alinhamento e adaptabilidade. É nesse contexto que prospera o empreendedorismo corporativo, como principal veículo de combinação das capacidades internas com as oportunidades externas. Neste caso, cabe à alta administração o papel de agregador e estimulador da ambidesteridade contextual.

Birkinshaw; Gibson (2004) observaram quatro comportamentos que suportam a ambidesteridade contextual nas empresas: a) indivíduos tomam a iniciativa e estão alertas a oportunidades, além das limitações dos seus trabalhos; b) indivíduos são cooperativos e procuram oportunidades para combinar seus esforços com outros colaboradores; c) indivíduos são intermediadores e estão sempre procurado construir relacionamentos internos; d) indivíduos são "multitarefa" e se sentem confortáveis "usando mais de um chapéu". Esses quatro atributos que conjuntamente descrevem um colaborador ambidestro têm algumas importantes características: eles constituem o agir fora dos limites estreitos do trabalho de alguém e tomam medidas para os interesses amplos da organização. Esses atributos descrevem indivíduos que são suficientemente motivados e informados para agir espontaneamente sem pedir permissão ou apoio de seus superiores. Esses indivíduos estão dispostos a ações que envolvem adaptações às novas oportunidades, mas são claramente alinhados com a estratégia do negócio. Assim, tais 
Leonel Cezar Rodrigues, Emerson Antonio Maccari \& Alexsandro Pereira

comportamentos são a essência da ambidesteridade contextual, a forma mais eficiente de ambidesteridade que promove o empreendedor corporativo e cria o contexto para a inovação. Portanto, ambidesteridade contextual pode ser entendida também como uma estratégia corporativa de auto-ordenação interna, cujo principal ator é o empreendedor corporativo.

\subsection{RESILIÊNCIA ORGANIZACIONAL - AUMENTANDO A IMUNIDADE ÀS PRESSÕES}

Reinmoeller; Baardwijk (2005) entendem que a resiliência organizacional é sua elasticidade às pressões do ambiente competitivo. Em outras palavras, a resiliência de uma empresa é sua capacidade de permanecer imune, isto é, manter sua participação no mercado e seu conseqüente desempenho financeiro estáveis, independentemente do tipo e volume da competição que enfrenta. Para tanto, argumentam os autores, a empresa precisa desenvolver um bom arsenal de capacidades internas, em termos de atributos corporativos, em termos de domínio tecnológico e em termos de capacitação em processos. O conjunto dessas capacidades internas, considerando sua resposta ao desempenho da empresa, resume-se na capacidade de inovar da mesma. Daí, resiliência organizacional ser também definida como a capacidade de uma empresa de auto-renovação por meio da inovação.

Quelhas; França (2006) referem-se ao processo de desenvolvimento de capacidades como a engenharia da resiliência. De fato, considerando-se não apenas a combinação, mas a otimização da combinação das capacidades de inovação que permite a uma organização manter-se, ou recuperarse rapidamente de situações não previstas, requer bons modelos combinatórios, integrando estratégias corporativas, organizacionais e competitivas de forma eficiente.

Para desenvolver e sustentar a resiliência organizacional, Reinmoeller; Baardijk (2005) apontam quatro estratégias distintas: (1) Administração do conhecimento - que envolve o uso e a alavancagem do conhecimento existente na organização como pressuposto para a inovação; (2) Cooperação interna - envolve mecanismos de capacitação interna para captação e exploração de idéias geradas no ambiente interno da organização; (3) Exploração - refere-se à busca e uso de novos recursos e capacitações, novas idéias e aplicações existentes no ambiente externo da empresa; e (4) Empreendedorismo corporativo - refere-se a estímulos e utilização de agentes internos (pessoas) capazes de explorar idéias e recursos através da experimentação e prototipagem.

Pode-se inferir dessas considerações que o empreendedorismo corporativo apresenta-se hoje como um mecanismo essencial para as empresas gerarem ou manterem sua trajetória de inovações

Revista Ibero-Americana de Estratégia - RIAE, São Paulo, v. 8, n. 2, p. 183-205, jul./dez. 2009. 
sustentadoras que lhes asseguram maior imunidade e continuidade em seus negócios.

\section{METODOLOGIA}

Esta pesquisa empírica teve uma abordagem qualitativa, utilizando-se para coleta e análise dos dados, o método de estudo de caso. Procura-se nesta pesquisa identificar as melhores práticas (ou estratégias internas) utilizadas pela empresa objeto, de estímulo ao empreendedorismo corporativo, em nível exploratório. A coleta dos dados foi realizada segundo o protocolo de coleta, análise e interpretação de dados qualitativos, de acordo com Yin (2005).

A empresa-objeto para esta pesquisa foi a Brasilata Embalagens Metálicas S/A, uma empresa premiada nacional e mundialmente por suas invenções e inovações e apontada como uma das dez empresas brasileiras mais empreendedoras no país (EXAME, 2005). Para a coleta dos dados, utilizou-se um roteiro de entrevistas aplicado aos sujeitos sociais (diretor superintendente, diretor de RH e um gerente em nível médio). Adicionalmente, coletou-se informações de documentos, relatórios internos da empresa e observações das rotinas e processos internos.

\section{ANÁLISE E INTERPRETAÇÃO DOS RESULTADOS}

\subsection{HISTÓRICO}

No ano de 1955, foi estabelecida em São Paulo, a Indústria e Comércio de Estamparia Brasung Ltda, que produzia tampinhas de folha-de-flandres para embalagens de cosméticos. Três anos depois, a empresa abriu seu capital e passou a fabricar latas para biscoitos e eletrodos. Em 1965, a compra da Estampbrás deu à Estamparia Brasung a base para sua experiência com litografia e o início da produção de latas para tintas e produtos químicos. Naquele mesmo ano, sua razão social foi alterada para Brasilata - embalagens metálicas S/A.

O grande crescimento econômico da década de 70, decorrente de forte investimentos externos e facilidade de aquisição de recursos para investimentos e expansão, foi um importante fator de crescimento para a Brasilata. Aproveitando-se do momento econômico favorável, a Brasilata adquiriu a Metalúrgica Brasilina S/A, tradicional fabricante de latas em São Paulo. No início dos anos 80, a Brasilata diversificou-se geograficamente, adquirindo as instalações da 
Leonel Cezar Rodrigues, Emerson Antonio Maccari \& Alexsandro Pereira

empresa gaúcha Killing Reichert S/A. Metalgráfica. Este foi um investimento estratégico que ajudou a ampliação de seu portfólio de produtos, com a introdução de baldes cônicos e cilíndricos. No ano de 1992, implantou a sua terceira unidade fabril, em Rio Verde - GO. Em 1999, a Brasilata adquiriu as linhas de aerossóis da Crown Cork Embalagens, instalando-as em sua unidade fabril em Estrela-RS, então recém ampliada. Correntemente, a Brasilata opera com as três unidades (São Paulo, Goiás e Rio Grande do Sul).

Os valores culturais da Brasilata estão definidos e fortemente divulgados para seus recursos humanos. Destacam-se como valores fundamentais o compromisso de longo prazo com os acionistas, funcionários, clientes e fornecedores. Mais característico, porém, é o papel da inovação como valor inalienável para garantir competitividade à empresa. Inovação é preocupação permanente da Brasilata, não só a voltada para produtos, mas também a voltada para as técnicas de gestão, que possam melhorar e flexibilizar seus processos.

\subsection{EMPREENDEDORISMO CORPORATIVO - A CONSTRUÇÃO DO PROCESSO}

Em 1985 a Brasilata, visando à melhoria da qualidade de seus produtos, iniciou a adoção das técnicas gerencias de produção japonesas, entre elas o Kanban e o Just-in-time. Em 1987, como resultado de demandas de processos adaptativos, originários dessas técnicas de gestão da produção e da qualidade, a empresa lançou o Projeto Simplificação, com o objetivo de melhorar sua eficiência com os novos processos. Assim, o Projeto Simplificação transforma-se num canal para captação de idéias para mudanças internas, especialmente voltadas para inovações em processos, embora algumas delas tenham resultado em novos produtos.

Um compromisso de não-demissão foi firmado em 1988 e, em 1990, teve início o processo de gestão participativa. Os gerentes, os supervisores e a diretoria passaram a participar efetivamente do processo de definição da visão, da missão, dos valores, das metas e das ações. Em 1991, foi implantado um sistema de incentivo monetário aos funcionários.

A crise econômica nacional, originada na abertura comercial do país, na primeira metade da década de 1990 forçou a empresa a tomar decisões acerca de sua estrutura, que se encontrava extremamente pesada (excesso de cargos, o que prejudicava a comunicação interna). Ainda assim, mantendo seus compromissos de não demissão, a Brasilata realizou uma reestruturação administrativa e operacional mediante um processo de reengenharia participativa, pelo qual os funcionários participaram do enxugamento da estrutura decidindo sobre demissões e cortes de cargos. Algo inusitado e de difícil realização já que a prática da reengenharia tem sido um processo

Revista Ibero-Americana de Estratégia - RIAE, São Paulo, v. 8, n. 2, p. 183-205, jul./dez. 2009. 
decisório de cima para baixo e, como tal, não dispensa uma boa dose de autoritarismo para que se efetive. Como resultados desses esforços, já em março de 2003, os funcionários receberam uma participação financeira, que em média representou quase um salário mensal adicional. A empresa havia alcançado uma marca histórica em sua lucratividade: 15\% do lucro líquido, após o imposto de renda.

\subsection{EMPREENDEDORISMO E INOVAÇÃO}

Tal crescimento deveu-se à estratégia interna da empresa de apostar em seus empreendedores internos. Segundo o Diretor Superintendente da Brasilata Sr. Teixeira Álvares, as inovações de produto e de processo "nascem num ambiente em que novas idéias são geradas por meio de permanentes brainstormings". As pessoas exercitam sua criatividade e sentem confiança para dar sua contribuição, porque elas percebem que a empresa não as deixa sem resposta e não as desampara. "Nossa empresa pratica uma ética coletiva, fundamentada no interesse pelos seus funcionários e pela comunidade a que serve," afirma o Sr. Teixeira.

Do estímulo à consolidação de seus valores, surgem os empreendedores corporativos, sob uma política institucionalizada de aposta na capacidade criadora de seus funcionários (a quem chama de inventores!). A Brasilata, então, passou a realizar uma intensa busca para a inovação de produtos e processos de seu portfólio. Como empresa de base manufatureira, a Brasilata passou a concentrar-se na inovação em seus processos. Assim, o Projeto Simplificação ganhou nova roupagem, em função das novas prioridades da empresa: a inovação incremental em produtos e processos. Essas prioridades transformaram a empresa num grande laboratório de identificação e teste de novas idéias. A geração de idéias segue um processo anárquico e pode voltar-se para qualquer área dentro da estrutura organizacional e dos processos da empresa. A empresa precisa ser flexível e orgânica para sustentar o afloramento do empreendedorismo. Nas palavras do Sr. Álvares,

“o empreendedorismo exige a capacidade de definir novas e diferentes configurações organizacionais, também implica em ação, exige autoconfiança, capacidade de olhar à frente...”

A operacionalização do Projeto Simplificação começa no chão de fábrica. As idéias sugeridas são previamente selecionadas por equipes julgadoras em cada uma das unidades. A Brasilata conta atualmente com uma equipe especialistas, responsável pelo teste prototipar das idéias, diretamente vinculada ao diretor superintendente. Essa equipe, criada já em 1997, é constituída por cinco técnicos experientes, que julgam a propriedade das idéias no contexto e para os interesses da empresa. Em nada se assemelha, porém, a uma equipe de P\&D.

Revista Ibero-Americana de Estratégia - RIAE, São Paulo, v. 8, n. 2, p. 183-205, jul./dez. 2009. 
Leonel Cezar Rodrigues, Emerson Antonio Maccari \& Alexsandro Pereira

Embora possua instrumental específico, o verdadeiro laboratório de testes é a própria empresa. Na Brasilata, todos os 900 funcionários têm liberdade para fazer seus experimentos, sob controle orientado de seus supervisores, testando a viabilidade técnica de suas idéias e dos respectivos processos de produção. Dessa forma, o funcionário é estimulado a apresentar idéias que possam melhorar o produto ou o processo, administrativo ou operacional, em grupo ou isoladamente.

\subsection{PROCESSO DE SUGESTÕES, ANÁLISE E SELEÇÃO DAS IDÉIAS}

Inovar é o perfil da Brasilata e por isso, a política de suporte ao empreendedorismo interno e de relacionamento de longo prazo entre a empresa e seus funcionários dão segurança às equipes que integram os 900 inventores de suas 3 unidades. $O$ incentivo à geração de novas idéias, especialmente as que se voltam para o aperfeiçoamento do processo produtivo (Projeto Simplificação), é reforçado pela intenção de manutenção longeva de seus funcionários.

Além da política organizacional de estímulo ao empreendedorismo há mecanismos internos na empresa que sustentam a realização dos projetos de inovação. Um sistema de recolhimento de idéias com análise preliminar por comissão interdepartamental revisora inicia o processo. As idéias podem ser propostas por indivíduos ou grupos. Em princípio, o processo mais estimulado é o de idéias em grupo, por causa da possibilidade de maior burilamento e visualização de sua exeqüibilidade no ambiente da empresa e da facilidade posterior de implementação da mesma. As idéias selecionadas recebem um patrocinador interno, com funções na alta hierarquia da empresa.

As idéias aprovadas preliminarmente são selecionadas para premiação, em etapas semestrais, segundo uma pirâmide das melhores idéias, com mais retorno, com maior impacto para a produtividade, abaixamento de custo, qualidade final dos produtos e desempenho geral da empresa. Em cada etapa são premiadas 6 idéias, por unidade. A premiação ocorre com evento festivo, com a participação de todos os inventores. Os premiados aparecem, com suas idéias, num telão e com suas fotos divulgadas num painel interno. Além disso, uma vez por ano, acontece a Supercopa, onde são escolhidas as melhores idéias de cada unidade (uma de cada unidade), dentre as que já foram selecionadas e premiadas. Na Supercopa, o(s) gerador(es) da inovação campeã tem a oportunidade de conhecer a unidade na qual será desenvolvida, se esta for fora de sua unidade.

Desta forma, a Brasilata é capaz de renovar-se estrategicamente, por meio da inovação, diversificação e aperfeiçoamento de seus produtos, processos e estruturas. Satisfazer as necessidades de seus empreendedores corporativos/invetores é, em tese, mais importante do que

Revista Ibero-Americana de Estratégia - RIAE, São Paulo, v. 8, n. 2, p. 183-205, jul./dez. 2009. 
satisfazer as necessidades de seus clientes. A premissa é de que haja uma transferência automática de interesse do funcionário para o cliente, pela satisfação do funcionário. Essa crença é assim expressa pelo se Diretor:

"a satisfação do nosso inventor vem antes da satisfação do cliente, porque se o nosso inventor estiver satisfeito, ele vai se preocupar com nosso cliente e vai também satisfazê-lo".

\subsection{MOTIVAÇÃO PARA INOVAÇÕES}

As ações relacionadas às políticas de estímulo ao empreendedorismo corporativo, o formato de gestão participativa, o compromisso de não demissão, mesmo em momentos de crise grave, tem contribuído para criar um clima de confiança nos empreendedores corporativos da Brasilata. A motivação para o avanço do empreendedorismo corporativo envolve vários fatores simultaneamente. Um deles é o formato da gestão por participação nos lucros, de todos os níveis da empresa. Os objetivos da participação estão definidos já no próprio planejamento estratégico da empresa, envolvendo desempenho corporativo, retorno aos stakeholders, qualidade e melhoria continua e aprendizado coletivo.

Um segundo fator, associado ao formato administrativo, é a política de estabilidade dos funcionários na empresa. Para gerar idéias que efetivamente aumentem o domínio tecnológico da empresa, é preciso um profundo conhecimento das estruturas, dos processos e da cultura da organização. Para isso, a Brasilata entende que seja necessária a construção de carreira de longo prazo, investindo sempre no aumento e a continuidade do relacionamento funcionário-empresa. Esse modelo de gestão é a base dos seus processos de inovação e tem feito com que a empresa ganhasse praticamente todos os prêmios de inovação conferidos às empresas do setor.

O prêmio mais importante, porém, no entendimento da diretoria da Brasilata, foi ter sido escolhida com uma das 100 melhores para se trabalhar no Brasil desde início da década. Assim, clima e cultura organizacional conducentes a um aprendizado experto e estimulado pela gestão do conhecimento são outros fatores essenciais, na visão dos executivos da Brasilata, para motivar a busca pela inovação.

A força da motivação, no entanto, não está restrita a motivadores de ordem extrínseca, como os apontados acima. De fato, esse conjunto de motivadores é o grande responsável pelo estímulo e aparecimento da motivação intrínseca, a principal alavanca para a produtividade de novas idéias. A Brasilata, assim, visa ao desenvolvimento e valorização do homem e da mulher na empresa, fundamentada no justo equilíbrio entre deveres e direitos. A política de relacionamento de longo

Revista Ibero-Americana de Estratégia - RIAE, São Paulo, v. 8, n. 2, p. 183-205, jul./dez. 2009. 
Leonel Cezar Rodrigues, Emerson Antonio Maccari \& Alexsandro Pereira

prazo com os funcionários estende-se também aos clientes e fornecedores e em seu ambiente comunitário. Seu relacionamento é pautado na confiança e consistência da oferta de produtos e serviços de valor e em sua responsabilidade pela vida dessas comunidades, especialmente pela preservação do meio ambiente.

A Brasilata acredita no valor positivo das comunicações transparentes e no acesso às informações, para o sucesso de seus negócios e para a qualidade do ambiente interno, motivação, comprometimento e participação de seus Inventores. Desta forma, disponibiliza canais de acesso e socialização da informação de três maneiras básicas: (a) Acesso à Internet/intranet: seus funcionários têm acesso à Intranet da empresa, para troca de informações internas, de idéias e conhecimento. Em cada unidade industrial existem computadores para acesso à Internet, por meio do CyberBrasilata.net, para acesso a e-mail e outras informações desejadas.

(b) Painéis de Informações: em cada unidade industrial existem vários painéis (Quadro de Avisos), localizados em áreas de grande circulação e de fácil visualização, permitindo a disseminação de informações importantes sobre os resultados do negócio, procedimentos, serviços e práticas de RH, "classificados", sociais, etc.

(c) Boletim Informativo: trimestralmente é editado o Boletim Informativo Brasilata, em suas pautas é oferecido espaço para notícias envolvendo atividades sócio-recreativas, bem como são encontradas informações sobre os lançamentos de novos produtos (muitos deles como fruto do Projeto Simplificação), resultados e conquistas da empresa, em seus mercados cada dia mais competitivos.

\subsection{OS IMPACTOS DA INOVAÇÃO NA BRASILATA}

Deste imenso laboratório de idéias da Brasilata, tem saído, nos últimos dez anos inúmeras idéias úteis aos objetivos estratégicos da empresa (financeiros e de mercado). As políticas institucionalizadas de estímulo ao empreendedorismo corporativo na Brasilata mostram que o retorno, por meio de idéias inovadoras, de melhoria na qualidade dos produtos, de novos design, de tecnologia de base e de eficiência em processos, é realmente compensador, pois tem gerado em números gerais:

Revista Ibero-Americana de Estratégia - RIAE, São Paulo, v. 8, n. 2, p. 183-205, jul./dez. 2009. 
- 6 patentes obtidas e usadas pela empresa. As inovações incorporadas nas patentes na forma de produtos de linha, respondem hoje por $75 \%$ das vendas da empresa, segundo informações do Diretor executivo.

- De acordo com os registros internos, até a data desta pesquisa, haviam sido averiguadas cerca de 45.800 idéias apresentadas pelos funcionários. Isso representa uma média de mais de 50 idéias por funcionário, ao longo dos últimos 10 anos. De acordo com o diretor entrevistado, do total de idéias selecionadas por terem sido julgadas úteis e exeqüíveis, $85 \%$ foram implementadas.

- A maioria das idéias gira em torno de pequenas melhorias de processo, fluxos de trabalho e simplificação de tarefas. Assim, a Brasilata tem calculado que a implementação dessas melhorias tem lhe dado um aumento de $81 \%$ na sua produtividade, durante esses últimos 10 anos.

\subsection{INOVAÇÕES DA BRASILATA - ENTRE AS 10 MELHORES DO BRASIL}

Entre as inovações mais importantes da Brasilata, a tecnologia de fechamento é apontada como uma das 10 mais criativas inovações. Mas essa capacidade de inovação vem de longo prazo. Segundo o Sr. Teixeira,

“a história da nossa inovação começa em 1995, quando a Brasilata introduziu no mercado brasileiro uma concepção inédita de fechamento que revolucionou e veio a substituir o padrão tradicional da lata para tintas, inventado em 1905..."

A inovação a que se refere Teixeira é um novo tipo de trava mecânica, o Fechamento Plus, uma solução premiada e patenteada internacionalmente, nos EUA, União Européia e Ásia. A inovação rendeu frutos, como a Biplus, considerada pela World Packaging Organization (WPO) como a melhor solução para tintas em cores personalizadas. E, para produtos alimentícios, a lata com o fecho Ploc Off desponta como a solução inovadora mais difundida, para embalagens de alimentos secos.

Como resultado das inovações, a Brasilata tem sido reconhecida como empresa inovadora no Brasil, na América Latina, Estados Unidos, Europa e Ásia. Nos últimos dez anos a Brasilata recebeu mais de 20 prêmios nacionais e internacionais, na América Latina, Estados Unidos, Europa e Ásia.

Revista Ibero-Americana de Estratégia - RIAE, São Paulo, v. 8, n. 2, p. 183-205, jul./dez. 2009. 
Leonel Cezar Rodrigues, Emerson Antonio Maccari \& Alexsandro Pereira

\section{CONCLUSÕES}

Como principais lições do caso Brasilata, pode dizer que, se por um lado, empreendedorismo corporativo representa um excelente caminho para a inovação, por outro, exige da administração da empresa a capacidade de definir novas e diferentes configurações organizacionais, ações claras e diretas no direcionamento dos problemas internos, e ao mesmo tempo, exige também autoconfiança e capacidade de visualizar o futuro de seus colaboradores.

A organização que busca usufruir dos benefícios que o empreendedorismo corporativo pode lhe trazer precisa estar atenta a três áreas de sensibilidade. Uma delas á a apropriação das estruturas organizacionais. Organizações burocratizadas, com estruturas mecanicistas não favorecem a emergência do empreendedorismo corporativo. É preciso desenvolver estruturas flexíveis, orgânicas e que permitam comunicação fácil e ampla. É preciso também prover regras claras para aumentar a eficiência do processo decisório, que nesses ambientes é mais participativo.

A segunda delas é a apropriação dos recursos humanos e das técnicas gerenciais à uma gestão participativa, orgânica e que permita a socialização dos conhecimentos. Os recursos humanos devem ser estimulados a exporem diretamente suas idéias e terem-nas devidamente consideradas pela empresa. Além disso, os gerentes precisam ser treinados para saberem lidar com o aparecimento de idéias novas e lidarem com a liderança informal que resulta da abertura para a livre iniciativa dentro da empresa.

Por fim, a terceira área de sensibilidade no processo de estímulo ao empreendedorismo são as estratégias corporativas. Os executivos precisam estabelecer e praticar políticas de apoio ao empreendedorismo, investir na construção de capacidades especiais e no desenvolvimento de mecanismos organizacionais de apoio à prática do empreendedorismo, especificamente, o sistema de avaliação de desempenho, o sistema de recompensa e o sistema de carreira profissional. Além', desses outros mecanismos de apoio interno devem ser planejados e implementados para assegurar a coleta eficiente de idéias e sua respectiva avaliação, como as caixas de idéias, os patrocínios, ou apadrinhamentos de idéias e outros.

Percebe-se que essas ações estavam presentes na Brasilata. Seus gerentes e funcionários estão conscientes e preparados para responder à dinâmica organizacional requerida pelas ações de empreendedorismo corporativo. Mecanismos de coleta de idéias, comitês de avaliação rápida, sistemas de premiação e reconhecimento das idéias exeqüíveis e utilizáveis pela empresa, são alguns exemplos da apropriação da empresa a seus empreendedores. Assim, não apenas é sustentado o esforço para a inovação, mas desenvolve-se a capacidade resiliente da empresa.

Revista Ibero-Americana de Estratégia - RIAE, São Paulo, v. 8, n. 2, p. 183-205, jul./dez. 2009. 
Finalmente, é importante notar-se ainda que, na empresa pesquisada, o empreendedorismo corporativo indiretamente tem sido o responsável pela diminuição dos índices de rotatividade e absenteísmo. A motivação decorrente da satisfação dos funcionários pela utilização de suas idéias, pelo prestígio junto a seus colegas de trabalho, pela premiação e noticiamento individual cria um senso de fidelização do funcionário à sua empresa. Isto gera adicionalmente, um maior envolvimento e compromisso dos funcionários com a empresa.

\section{REFERÊNCIAS}

Adizes, I. (1996). Os Ciclos de Vida das Organizações. São Paulo: Pioneira.

Austin, Robert D., Nolan, Richard L. ( 2007). Bridging the Gap Between Stewards and Creators. MIT Sloan Management Review, v. 48, n.2, p. 29-36.

Bastos, R.C.; Bastos, L.C. (1999). Success Factors Determination for Entrepreneurs in Santa Catarina by using neural Networks. In: International Joint Conference on Neural Network. Washington (DC). Anais do ...v. 5, p. 3556-3559.

Birkinshaw, J. (1997). Entrepreneurship in Multinational Corporations: The Characteristics of Subsidiary Initiative. Strategic Management Journal, v. 18, n. 3, p 207-230. http://dx.doi.org/10.1002/(SICI)1097-0266(199703)18:3<207::AID-SMJ864>3.3.CO;2-H http://dx.doi.org/10.1002/(SICI)1097-0266(199703)18:3<207::AID-SMJ864>3.0.CO;2-Q

Birkinshaw, J., Gibson, Cristina. (2004). Building Ambidexterity into your Organization. MIT Sloan Management Review, v. 45, n.4, p. 47-55.

Block, Z.; Macmillan, I. C. (1993). Corporate Venturing: Creating New Businesses Within the Firm. Cambridge: Harvard Business School Press.

Dolabela, Fernando. (1999). O Segredo de Luiza. São Paulo: Cultura Editores.

Dornelas,Jose Carlos Assis. (2001). Empreendedorismo Corporativo.São Paulo: Campus.

Drucker, Peter F. (1986). Inovação e Espírito Empreendedor: prática e princípios. São Paulo: Ed. Pioneira.

Revista Ibero-Americana de Estratégia - RIAE, São Paulo, v. 8, n. 2, p. 183-205, jul./dez. 2009. 
Leonel Cezar Rodrigues, Emerson Antonio Maccari \& Alexsandro Pereira

Exame. Revista Exame. (2005). Empreendedorismo nas Empresas Brasileiras. Edição 856. São Paulo: Editora Abril.

Farrel, Larry C. (1993). Entrepreneurship: fundamentos das organizações empreendedoras. São Paulo: Atlas.

Filion, L. J. (1999). Empreendedorismo: Empreendedores e proprietários-gerentes de pequenos negócios. Revista de Administração da USP, v.34, n.2, p.05-28, abr/jun.

. (2000). Empreendedorismo e gerenciamento: processos distintos porém complementares. Revista de Administração de Empresas, v.40, n.3, Jul./Set.

. (1993). Visão e relações: elementos para um metamodelo empreendedor. Revista de Administração de Empresa da Fundação Getúlio Vargas, v.33, Nov-Dez, p.50-61.

Georgescu, P. O poder é do consumidor. (1998). Gazeta Mercantil. p. C-8, 12/01/1998.

Gimenez, Fernando A. P.; Junior, Edmundo Inácio; Sunsin, Luzia A. de S. B. (2001). Uma investigação sobre a tendência do comportamento empreendedor. In: Souza, Eda Castro Lucas de. Empreendedorismo: competência essencial para pequenas e médias empresas. Brasília: ANPROTEC.

Ghoshal, Sumatra; Bartlett, Christopher. (1999). The Individualized Corporation. New York: HarperCOllins.

Hamel, G.; Prahalad, C. K. (1995). Competindo pelo futuro. Rio de Janeiro : Campus.

IBIE - Instituto Brasileiro de Intra-Empreendedorismo. (2006). O Valor das pessoas no desafio de inovar. Revista Exame. Ed. 864, ano 40, no. 6, p. 65-78.

Jennings, D.; Lumpkin, J. (1989). Functionally modeling corporate entrepreneurship: An empirical integrative analysis. Journal of Management, v.15, p. 485-502.

http://dx.doi.org/10.1177/014920638901500310

Kanter, R. M. (1982). The Middle Manager as Innovator. Harvard Business Review, n. 61, p. 95105.

Manyicka, J.M., Roberts, R.P., Sprague, K.L. (2007). Eight Business Technology Trends to Watch. McKinsey Quarterly, Online Premium Edition, December.

Mcclelland, David C. (1961). The achieving society. New York: Van Nostrand. 
Mintzberg, H. (1987). The strategy concept I: five Os for strategy. Califórnia Management Review, p.11-24, Fall.

Nadler, D.A.; Tushman, M.L. (1997). Competing by Design. New York: Oxford University Press. http://dx.doi.org/10.1093/acprof:oso/9780195099171.001.0001

Oslo - Manual de Olso. (1997). Diretrizes para Coleta e Interpretação de Dados sobre Inovação. $3^{\mathrm{a}}$ edição. OECD.

Pati, V. (1995). O empreendedor: descoberta e desenvolvimento do potencial empreendedor. In: Santos, S. A.; Pereira, H. J. (Orgs.) Criando seu próprio negócio: como desenvolver o potencial empreendedor. p.41-62, Brasília: SEBRAE.

Peters, Thom, Waterman, Robert. (1982). In Search of Excellence. New York: HarperCollins.

Pinchot III, G e Pellman, R. (2004). Intra-empreendedorismo na prática: um guia de inovação nos negócios. Rio de Janeiro: Elsevier.

Pinchot III, G. (1978). Intra-Corporate Entrepreneurship, Fall.

Pinchot III, Gifford. (1989). Intrapreneuring: porque voce não precisa sair da empresa para tornar-se um empreendedor. São Paulo: Harbra.

Prahalad, C. K.; Hamel, G. (2005). Competindo pelo futuro. 19a . ed. Rio de Janeiro : Campus.

Quelhas, O. L. G.; França, S. L. B. (2006). Análise de fatores para gestão de mudanças: Gestão do Conhecimento, Intra-empreendedorismo e Engenharia de Resiliência, XXVI ENEGEP Fortaleza, CE, Brasil, 9 a 11 de Outubro de 2006.

Reinmoeller, Patrick; Baardwijk, Nicole Van. (2005). The Link Between Diversity and Resilience. MIT Sloan Management Review, v. 46, n.4, p. 61-66.

Schumpeter, Joseph Alois. (1982). The Theory of Economic Development: An Inquiry into Profits, Capital, Credit, Interest and the Business Cicle. Reimpressão. Piscataway (NJ): Transaction Publisher.

Tidd, J.; Bessant, J.; Pavitt, K. (2005). Managing Innovation: integrating technological, market and organizational change. 3a edição, West Sussex: John Wiley \& Sons.

Tushman, Michael; O’reilly, Charles. (1997). Wining Through Innovation. Boston (MA) : Harvard University School Press.

Revista Ibero-Americana de Estratégia - RIAE, São Paulo, v. 8, n. 2, p. 183-205, jul./dez. 2009. 
Twiss, B. (1992) Managing Technological Innovation. New York: Longman.

Vérin, H. (1982). Entrepreneurs, entreprises, histoire d'une idée. Paris: Presses.

Vries, Kets de; Manfred, F. R. (2001). Rebeldes criativos com causa. In: Birley, Sue; Muzyka, Daniel F. Dominando os desafios do empreendedor: seu guia para se tornar um empreendedor. São Paulo: Makron.

Zahra, Shaker. (1991). Predictors and financial outcomes of corporate entrepreneurship: an explorative study. Journal of Business Venturing, n. 6, p. 259-285.

Yin, Robert. ( 2005). Estudo de caso. Porto Alegre: Bookman.

Recebido: 26/08/09

Aprovado: 16/11/09

Revista Ibero-Americana de Estratégia - RIAE, São Paulo, v. 8, n. 2, p. 183-205, jul./dez. 2009. 